DOI: http://dx.doi.org/10.23925/2176-2767.2019v65p435-449

Recebido em: 30/03/2019 Aprovado em: 11/05/2019

\title{
NOTÍCIA
}

\section{A ATUAÇÃO DA IMPRENSA NA REORGANIZAÇÃO POLÍTICA EM PERNAMBUCO EM 1954}

\author{
DANIEL FRANCISCO DA SILVA*
}

Este trabalho tem como objetivo problematizar inquietações levantadas no decorrer da escrita da minha dissertação de mestrado desenvolvida na Pontifícia Universidade Católica de São Paulo. A pesquisa em andamento tem como eixo temático a análise da imprensa pernambucana, atentando para sua atuação na reorganização política do estado após o suicídio de Getúlio Vargas, em agosto de 1954. Destarte, ao trabalharmos com a imprensa no Brasil, temos como principal referencial a obra: História da Imprensa no Brasil, ${ }^{1}$ de Nelson Werneck Sodré publicada em 1999. Em sua $4^{a}$ edição, o livro apresenta um tópico intitulado O pensamento de Nelson Werneck. Sodré sobre a imprensa e os meios de comunicação de massa no Brasil, nos últimos anos. Nesse item o autor discute como a imprensa surgiu no capitalismo e de que maneira o seu desenvolvimento está atrelado a esse modelo econômico. Para o autor, o capitalismo contribui de forma muito intensa no sentido de influenciar os chamados meios de massas, como por exemplo o rádio e depois a televisão. Assim, Sodré apresenta uma discussão na qual a imprensa exerce um papel fundamental na sociedade. Contudo, tal imprensa está 
imersa nos controles do capitalismo, relação que irá culminar em diferentes posicionamentos acerca do que é publicado.

Dessa forma, Sodré chama atenção para a destituição de dois presidentes no Brasil ocasiões em que, segundo o autor, a imprensa foi o principal ator. "Em agosto de 1954, jornais e rádios habitualmente consorciados empresarialmente, montaram uma operação que levou o presidente Vargas ao suicídio, praticamente já deposto em três semanas, entre 5 e 24 de agosto; em 1964, dez anos depois, jornais, rádios e televisão, trabalhando unidos para a tarefa, levaram o presidente Goulart ao exílio". 2 Portanto, a imprensa exerce um papel de influência na sociedade. Sodré adverte para pensarmos a maneira como esse setor, agora, está imerso no neoliberalismo brasileiro, pois, segundo ele, "a imprensa oligopolizada e vinculada à estrutura social e política vigente definiu a sua alienação e perdeu qualquer traço do que é nacional aqui. A alienação é o seu retrato"’3. A crítica desenvolvida por Nelson Werneck Sodré centra-se na ideia de que a imprensa está conectada às questões econômicas do século XX e imbricada nos interesses ligados a grupos hegemônicos no Brasil. Assim, percebemos o quanto esse segmento obteve papel relevante na conjuntura política de 1954 que, posteriormente, culminou no suicídio do então presidente Getúlio Vargas e na recomposição dos quadros políticos não só em Pernambuco, mas em todo Brasil.

Nesse sentido, partimos do pressuposto de que a imprensa é uma linguagem constitutiva do social e que atua de forma ativa na sociedade, como nos propõe Raymond Williams. ${ }^{4}$ Sendo assim, os jornais pesquisados, Correio do Povo e Diário de Pernambuco, intervêm na 
reorganização política em Pernambuco após o suicídio de Getúlio Vargas, uma vez que esses periódicos se posicionaram junto à sociedade pernambucana, no processo do pleito de outubro de 1954, por meio de manchetes, reportagens, fotografias e editoriais. Portanto, a imprensa é o objeto e fonte em nossa pesquisa. Destarte, Cruz e Peixoto nos auxiliam a compreender a imprensa de forma metodológica:

[...] Metodologicamente [...] não se trata de a cada análise de uma publicação específica voltar às origens ou as linhas gerais da articulação da imprensa ao processo de formação da sociedade burguesa. Implica, sim, em trazer para cada conjuntura e problemática que se investiga os desdobramentos teóricos e metodológicos que ela encaminha, articulando a análise de qualquer publicação ou periódico ao campo de lutas sociais no interior do qual se constitui e atua. ${ }^{5}$

Dessa forma, a imprensa pernambucana se constituiu no espaço em que as correlações de forças políticas se apresentaram e influenciou na disputa, com implicações nos resultados eleitorais, pela construção de memórias que estabeleceram relações com Getúlio Vargas. Haja vista que a imprensa é sujeito ativo nessa dinâmica e que atua de forma direta no processo eleitoral. Nesse sentido, Thompson ${ }^{6}$ nos subsidia a problematizar a história como disciplina independente e que tem seu próprio método. Sendo assim, a pesquisa histórica precisa ser problematizada a partir do diálogo com a fonte. A experiência é fator determinante para que possamos compreender o sujeito e o processo histórico a ser analisado.

A imprensa recifense, vista como fonte para o historiador, nos remete a problematizar as experiências modificadas por esses sujeitos 
sociais ativos, uma vez que ela atua na sociedade pernambucana, com destaque para os jornais Correio do Povo e Diário de Pernambuco. Pois, "O historiador deve tecer a trama de sua narração com os fios da experiência: a sua e a dos outros, de modo que seu relato possa a ser incorporado à experiência de seus leitores, ouvintes, etc.".7 O historiador remete-se a problematizar os anseios sociais emudecidos que se encontram na imprensa pernambucana. Portanto, concordamos com a historiadora Peixoto que:

fazer história é compartilhar experiências, mesmo que, para isso, tenhamos que ouvir os silêncios que escondam outra história que não as dos vencedores, repondo para seus protagonistas o espaço que lhes foi suprimido, libertando - não para o passado, mas em sua memória - o grito que ainda trazem preso à garganta. ${ }^{8}$

Sendo assim, as experiências compartilhadas pelos sujeitos sociais, e que foram silenciadas na imprensa pernambucana, são reflexos de qual história poderia ser contada acerca da conjuntura política após o suicídio de Getúlio Vargas, em agosto de 1954, de acordo com a visão de cada grupo jornalístico em Pernambuco. Por isso, é necessário realizarmos uma história a contrapelo como nos propõe Walter Benjamim. ${ }^{9}$

Nessa seara, problematizarmos o perfil do grupo jornalístico é de suma importância para que possamos compreender a linha editorial e com quais grupos políticos e econômicos esses jornais estabeleceram relações, uma vez que a imprensa constitui memórias, mas tem seus próprios interesses. Nesse sentido, O Correio do Povo será o fio condutor da nossa investigação, dado que o jornal se apresenta no cerne da 
discussão política recifense, corroborando com o grupo político varguista em Pernambuco. Assim, o veículo traz uma gama de matérias evidenciando as manifestações de pesar do suicídio do presidente Getúlio Vargas, em Recife - PE. Nestas publicações os trabalhadores têm espaço para externarem seus sentimentos de pesar. O periódico também apresenta a ligação política com a candidatura de João Cleofas UDN.

O Correio do Povo conta com uma gráfica própria - Gráfica Correio do Povo Ltda. ${ }^{10}$ Esse jornal é um matutino que nasceu em 05 de agosto de 1954, em meio ao publicismo e à crise política que o segundo Governo Vargas (1951-1954) enfrentou. Contudo, essa folha surge em hora propícia para constituir uma propaganda para o grupo político do ex-Ministro da Agricultura de Getúlio Vargas - João Cleofas. Outrossim, o Correio do Povo irá tecer críticas severas ao grupo político do Governador de Pernambuco, Etelvino Lins, do PSD. O jornal atuará de forma ativa durante as manifestações de pesar do suicídio de Getúlio Vargas e, sobretudo, nas articulações políticas para o pleito de 03 de outubro de 1954.

Outro jornal pesquisado é o Diário de Pernambuco - ainda em circulação - pertencente aos Diários Associados de Assis Chateaubriand. ${ }^{11}$ Grupo jornalístico influente no Brasil e que tem uma agência de notícias própria: a meridional. O jornal também publica notícias de agências internacionais. Muitas matérias da imprensa estrangeira serão republicadas em Recife-PE acerca do pesar das autoridades no exterior ao saberem da notícia do suicídio do presidente Getúlio Vargas. Esse jornal nos subsidiará no confronto de visões acerca da temática estudada, 
pois, em determinados momentos, Os Diários Associados apresentavam posições divergentes em relação ao governo Vargas. Em outros momentos, o jornal se alinhava a posturas varguistas e, no âmbito estadual, o Diário de Pernambuco irá trazer publicações de propagandas da candidatura de João Cleofas para Governador do Estado.

Uma das principais diferenças entre os dois jornais se evidencia na diagramação. O Correio do Povo utiliza uma linguagem gráfica em que as fotografias têm bastante evidência e as manchetes dialogam entre si. Já o Diário de Pernambuco privilegia as manchetes com relevância escrita e não o uso excessivo de fotografias em suas capas, como seu concorrente. Sendo assim, as posições dos jornais, em determinados momentos, são antagônicas e, em outros, convergentes. Logo, a atuação dos dois periódicos na reorganização política em Pernambuco fica mais evidente nas páginas em que atuam de forma diversificada, com publicações acerca dos grupos políticos que estão disputando as eleições de outubro de 1954, constituindo, assim, memórias dos sujeitos em que estão em confronto.

A historiadora Déa Fenelon nos subsidia a compreender a memória como campo de disputas. Assim, o jornal Correio do Povo é um órgão que dá espaço para os feitos dos governos getulista em Pernambuco e que atuou, durante o processo das manifestações populares, na construção da memória de Getúlio Vargas na cidade de Recife - PE. Ocasião em que o povo se apresentou no espaço público para externar seus sentimentos ao chefe da nação que acabara de partir e que tece uma relação com as manifestações pela candidatura de João Cleofas. Fenelon contribui para pensarmos a "memória em constante 
mudanças, como um campo de luta, como alvo de disputa, de domínio e de afirmação social", ${ }^{12}$ uma vez que, nesse processo, a memória constituída pelo jornal interliga a conjuntura política nacional e estadual em que estava inserido.

Nesse sentido, os jornais pesquisados nos apresentam o quanto eles compuseram as correlações de forças envolvidas nos antagonismos partidários que se apresentaram no cerne do debate da conjuntura política de 1954, após o suicídio de Getúlio Vargas, dinâmica na qual irão estabelecer uma relação com a memória do presidente morto. Como visto, essa disputa de legado se apresenta na conjuntura de 1954 em que, na imprensa pernambucana, as eleições de outubro estavam no centro do debate público e na qual as manifestações populares de pesar pelo suicídio de Getúlio Vargas ocorridas no estado irão corroborar com a contenda eleitoral noticiada pelo Correio do Povo, já que esse jornal atuará veementemente na construção de uma memória de Getúlio ligada a um grupo político local, o Movimento Popular Autonomista de Pernambuco. Dentre outras agremiações partidárias, esse núcleo se articulou com forças políticas divergentes, como por exemplo a União Democrática Nacional - UDN, o Partido Trabalhista Brasileiro - PTB (ala dissidente do Partido Social Democrático PSD) e o Partido Social Trabalhista - PST - para concorrer ao Executivo Estadual ${ }^{13}$. Foi escolhido o nome do usineiro João Cleofas como candidato desse grupo. Ele concorreu contra Osvaldo Cordeiro de Farias, do PSD, indicação do Governador de Pernambuco, Etelvino Lins, filiado ao mesmo partido.

Os jornais Correio do Povo e Diário de Pernambuco já trazem, em suas edições do início de agosto de 1954, matérias sobre as tratativas de uma 
união da classe política pernambucana para vencer o candidato do PSD. Como coberto pelo Correio do Povo na matéria intitulada Hoje a escolha dos rumos da dissidência. ${ }^{14}$ Aqui o jornal, em sua primeira edição de circulação, já se apresenta como sujeito ativo para que a candidatura de oposição ao PSD se torne viável. Assim, a matéria aponta detalhes de como a ala pessedista discordou da posição do Governador Etelvino Lins em lançar o general Cordeiro de Farias para Governador de Pernambuco. O jornal noticia que haverá uma reunião "à noite na casa do sr. Jarbas Maranhão [...] Que o coelho saia dos dissidentes está um pouco difícil, não se tenha a menor dúvida. Entretanto tenham paciência os leitores e vamos aguardar por mais algumas horas o descascamento do abacaxi”. ${ }^{15}$

Desse modo, esse veículo estabelece uma relação clara com o leitor em que traz para o cerne da discussão o processo da crise interna pelo qual o PSD pernambucano passou durante o pleito de 1954. O Correio do Povo já aponta que os dissidentes não irão conseguir tirar um nome para contrapor ao do general Cordeiro de Farias. Dessa forma, a crise interna do PSD irá culminar em um apoio de suma importância para o candidato udenista - João Cleofas. O jornal Correio do Povo publicará no dia 07 de agosto, na primeira página, a manchete "enfim: a dissidência apoia João Cleofas". ${ }^{16}$ Esse apoio da dissidência virá com exigências ao PTB e a UDN. Essas exigências perpassarão pela composição da chapa eleitoral, O:

apoio a Cleofas mediante [a] condições - eis a palavra de ordem da dissidência pessedista [...] [dentre os acordos estão] 1. duas senatorias para a Dissidência; 2. Não apresentação do nome de Barros de Carvalho, ainda que na legenda do PTB isoladamente; 3 Apoio dos comunistas a Cleofas, 
para assegurar a vitória por uma larga margem, no Recife; 4 Três Secretarias do Estado, no futuro Governo; 5 condições de financiamento de campanha. ${ }^{17}$

As tratativas da dissidência trarão novos embates políticos para que o grupo do PTB e da UDN possam contar com esse apoio em seu palanque eleitoral. Sendo assim, o jornal Correio do Povo inicia sua trajetória na imprensa pernambucana cobrindo os meandros da candidatura de João Cleofas e se posicionando a favor dessa união do PTB, UDN e da dissidência do PSD. Por conseguinte, essa união dos partidos em prol de João Cleofas perpassa pelas publicações do Correio do Povo que atua em apoio das alianças constituídas para viabilizar a candidatura de Joao Cleofas. Assim, o periódico publica trechos de matérias em que o governador de Pernambuco está afastando o operário da vida pública, como veremos claramente na manchete Esquema Etelvino: Afastamento do operariado da vida pública. ${ }^{18}$

Essa matéria traz trechos da fala do presidente do PTB Nacional, João Goulart. Ele faz um paralelo entre as demandas dos trabalhadores defendidas pelo seu partido e classifica a política do Governador Etelvino Lins como "esquema reacionário" e que, "tem, como objetivo afastar, sobretudo, os operários da vida política nacional". ${ }^{19}$ Dessa forma, o jornal procura dar evidência para a fala de João Goulart que, contribui para fortalecer as articulações políticas para a candidatura de João Cleofas.

Destarte, a imprensa pernambucana interveio por meio de suas publicações para que o povo do estado escolhesse seus representantes. O 
Diário de Pernambuco publicou no dia 04 de agosto a matéria intitulada Pernambuco: Escolha seu candidato para Governador.

Nessa matéria, o jornal elenca traços biográficos dos dois candidatos e os feitos que eles realizaram para o estado de Pernambuco,

JOÃO CLEOFAS DE OLIVEIRA, pernambucano, civil e engenheiro, realizou em Pernambuco o seguinte:

JOÃO CLEOFAS instalou em Pernambuco, em Tamandaré a primeira Escola de Pesca do Brasil para formação de pescadores e educação de filhos de pescadores. Antes de JOÃO CLEOFAS no Ministério da Agricultura, Pernambuco possuía 16 tratores. Hoje, 125 tratores acham-se distribuídos nos diversos municípios do Estado ajudando os agricultores na batalha da mecanização da lavoura.

28 mil hectares de terras preparadas constituem a atividade do último ano da administração de JOÃO CLEOFAS à frente do Ministério [...]

A mecanização da lavoura no Brasil é hoje, uma realidade graças sobretudo ao espírito empreendedor de JOÃO CLEOFAS.

JOÃO CLEOFAS criou em Pernambuco o primeiro centro de formação de tratoristas do Nordeste [...] GENERAL CORDEIRO DE FARIAS, gaúcho e militar realizou em Pernambuco o seguinte: [o jornal publica um quadro em branco sobre as realizações de Cordeiro de Farias] QUAL DOS DOIS, MERECE SEU VOTO, PERNAMBUCANO?20

Nesse sentido, o Diário de Pernambuco evidenciou os dados biográficos de João Cleofas, fazendo com que esse homem pernambucano e que realizou feitos por Pernambuco quando esteve à frente do Ministério da Agricultura se destacasse na corrida para o pleito de 1954 contra o general Cordeiro de Farias. Assim, os dois jornais pesquisados convergem nesse momento na direção de apoio à 
candidatura do usineiro João Cleofas. Percebemos que a união desses partidos tem João Cleofas como representante do Movimento Autonomista Popular, que se dá na perspectiva de resistir ao poderio do Governador Etelvino Lins, que se articulou não só para conseguir eleger Cordeiro de Farias governador de Pernambuco, como também viabilizar a sua candidatura para presidente da República, em 1955.

O cenário político pernambucano para o pleito de 1954 se configurará da união desses partidos divergentes. Contudo, convergem em prol do nome de João Cleofas -UDN, para que possam disputar as eleições com chances reais de vencer a candidatura do PSD, representada por Cordeiro de Farias. Nesse sentido, os vários partidos se unem com o objetivo de aposentar da política pernambucana o PSD, que havia se consolidado no poder. Por isso, UDN, PTB, dissidente do PSD e o Partido Comunista, irão disputar as eleições estaduais pernambucanas contra o grupo do Governador Etelvino Lins. Nessa situação, a candidatura de Cordeiro de Farias, do PSD, irá encontrar uma resistência maior do que a esperada, uma vez que os partidos de oposição se uniram em prol de um grupo para derrotar o partido. Contudo, o PSD se apresenta forte nessas eleições de 1954, pois o Governador Etelvino Lins desempenhará um papel importante junto à candidatura pessedista. A ideia de Lins de apoiar o nome de Osvaldo Cordeiro de Farias para concorrer ao governo do estado se apresenta com a proposta de um candidato extrapartidário, já que a conjuntura política brasileira se encontrava em momentos de crise econômica e política. É nesse cenário que o nome de Cordeiro de Farias é escolhido para disputar as eleições estaduais pernambucanas. 
Etelvino Lins, ao chancelar o nome de Cordeiro de Farias como candidato extrapartidário, se preocupa em apresentar o PSD como um partido que pode também ser protagonista na oposição à Vargas, e o PSD pernambucano terá esse papel, uma vez que João Cleofas fez parte do Governo Vargas (1951-1954). E o nome de Cordeiro de Farias é escolhido com o propósito de trazer para o cerne do debate as questões da conjuntura nacional e o descrédito da população nos partidos.

Dessa forma, o Diário de Pernambuco e o Correio do Povo se posicionaram acerca da candidatura de João Cleofas trazendo propagandas e exaltando o candidato. Tal processo acontece em Pernambuco, pois essa candidatura representava a alternância de poder no Executivo estadual, sobretudo, por derrotar o PSD ligado ao exgovernador Agamenon Magalhães - um dos principais nomes da política pernambucana na primeira metade do século XX.

Assim, percebemos que os jornais Correio do Povo e Diário de Pernambuco estabelecem convergência na defesa do nome de João Cleofas com interesses políticos que já se apresentam de pleitos anteriores. Haja vista que o PSD de Agamenon Magalhães contava com um forte apoio no interior de Pernambuco. Contudo, nas eleições de outubro de 1954 parte da ala pessedista rompe com o Governador Etelvino Lins para apoiar João Cleofas - UDN. E esse apoio passa pelas páginas dos dois jornais pesquisados. A imprensa irá atuar e intervir no pleito, momento em que estabelece uma relação com o público leitor. Tal fato se dará em suas publicações acerca dessa mudança no cenário político brasileiro, no qual o suicídio de Getúlio Vargas possibilitou a recomposição política 
em Pernambuco e, sobretudo, o crescimento do PTB no poder Legislativo estadual e nacional.

Atenta a esse quadro, a pesquisa em andamento busca compreender a atuação da imprensa de Pernambuco no processo de reorganização política no estado, após o suicídio de Getúlio Vargas. As eleições de 03 de outubro de 1954 aconteceram em um momento delicado da conjuntura política brasileira em que as articulações políticas se apresentaram de forma diversa, tendo a imprensa atuado de forma marcante. Sobretudo o jornal Correio do Povo, que constrói a candidatura de João Cleofas em suas páginas promovendo diálogo das manchetes do jornal com a propaganda política diária do "êle fêz", do udenista. Essa ação tinha como objetivo publicar os feitos que o ex-ministro da Agricultura do Governo Vargas fez para o povo pernambucano, quando esteve no comando da pasta.

O Diário de Pernambuco também irá publicar essa campanha, todavia, não será com a mesma evidência que o seu concorrente. O Diário publicou esse cartaz em páginas aleatórias nas quais a diagramação não destaca os diálogos da mesma forma que o verificado no Correio do Povo. Desse modo, a imprensa pernambucana atuou na construção da imagem de João Cleofas interligando com o que ele fez no Ministério da Agricultura e se posicionando no sentido de que essa candidatura era a que representava a democracia em Pernambuco. Enquanto que a candidatura de Cordeiro de Farias - PSD - era a representação da obscuridade e dos inimigos que levaram Getúlio Vargas a cometer o suicídio em 24 de agosto daquele ano. Dessa forma, a imprensa pernambucana intervém na sociedade com o objetivo de que aconteça 
alternância de poder no Executivo estadual. Todavia, as maiores mudanças na política local aconteceram na Assembleia Legislativa de Pernambuco.

Como destacado, a pesquisa em andamento está analisando o processo de reorganização política em Pernambuco após as eleições de outubro de 1954, buscando também entender como os jornais Correio do Povo e Diário de Pernambuco se posicionaram diante do resultado desse pleito, com a derrota de João Cleofas para Cordeiro de Farias.

\section{Notas}

\footnotetext{
* Mestrando em História Social pela Pontifícia Universidade Católica de São Paulo PUC-SP. Bolsista do Conselho Nacional Cientifico e Tecnológico - CNPq. E-mail para contato: daniel-silva-07@live.com https://orcid.org/0000-0001-9677-2627

${ }^{1}$ SODRÉ, N. W. História da Imprensa no Brasil. 4. Ed. Rio de Janeiro: Maud. 1999.

2 op. cit. p. XIV.

3 op. cit. p. XVIII

${ }^{4}$ WILLIAMS, R. Marxismo e Literatura. Rio de Janeiro: Zahar, 1979.

${ }^{5}$ CRUZ, H. de F.; PEIXOTO, M. do R. C. Na oficina do Historiador: Conversa Sobre História e Imprensa. Projeto História, São Paulo, no 35, p. 257. Educ, 2007.

6 THOMPSON, E. P. A miséria da Teoria ou um planetário de erros uma crítica ao pensamento de Althusser. Rio de Janeiro: Zahar, 1981. p. 182.

7 PEIXOTO, M. do R. da C. Um dedo de prosa. In: O Trem da História. A aliança PCB/CSCB/O PAÍS. Rio de Janeiro, 1923/1924. São Paulo: Editora Marco Zero, 1999. p. 10.

8 idem.
}

9 BENJAMIM, W. Teses Sobre o conceito de História. In:

Magia e Técnica, Arte e Política. São Paulo: Ed. Brasiliense, Vol. 1, 1985.

10 Estrutura administrativa da gráfica e do periódico; Diretor Presidente: Antônio de Barros Carvalho; Diretor-Superintendente: Edgar Bezerra Leitz; Diretor do Correio do Povo: Josemar Moreira de Melo

${ }^{11}$ Fundado no ano de 1825 por A. J de Miranda Falcão. Diretor Assis Chateaubriand Redação e administração - Praça da Independência, 12 - Recife - PE.

12 FENELON, D. Apresentação. In: MACIEL. L. A.; ALMEIDA. P. R. de; KHOURY. Y. A. (Org). Outras Histórias: Memórias e Linguagens. São Paulo: Olho d'Água, 2006. p. 8.

13 Correio do Povo, Recife - PE. 10. ago. 1954. p. 3.

${ }^{14}$ Correio do Povo, Recife - PE. 05. ago. 1954. p. 3. 
15 Idem.

${ }^{16}$ Correio do Povo, Recife, PE. 07. ago. 1954. p. 1.

17 Ibid. p. 3.

${ }^{18}$ Correio do Povo, Recife, PE. 08. ago. 1954. p. 2.

${ }^{19}$ Idem.

${ }^{20}$ Diário de Pernambuco, Recife - PE. 04. ago. 1954. p. 3. 